\title{
Evaluation of the shear bond strength of ceramic orthodontic brackets to glazed monolithic zirconia using different bonding protocols
}

\author{
Youmna Emad Douara ${ }^{1}$, Saly Mohamed Abdul Kader ${ }^{2}$ \\ Hassan Elsayed Kassem ${ }^{3}$, Mohamed Ibrahim Mowafy ${ }^{4}$
}

A6stract

AIM: The aim of this study was to evaluate the shear bond strength (SBS) of ceramic brackets to glazed monolithic zirconia using three different bonding protocols.

MATERIALS AND METHODS: Forty-five monolithic glazed zirconia embedded into acrylic resin were randomly assigned to 3 groups $(n=15)$ following air abrasion by $50 \mu \mathrm{m}$ aluminum oxide particles, the groups were treated with: (A) Assure Plus, (B) Silane + Assure Plus (C) Hydrofluoric acid + Silane + Transbond XT primer. Ceramic brackets were bonded to the zirconia discs using Transbond XT. Following thermocycling $\left(500\right.$ cycles, $\left.5^{\circ}-55^{\circ} \mathrm{C}\right), S B S$, failure mode and Adhesive Remnant Index were assessed.

RESULTS:Group C showed the highest SBS followed by Group $B$ with no statistically significant difference. Most of the specimens in Group C showed an adhesive failure between the bracket base and the adhesive, whereas Group $B$ presented mainly a mixed cohesive adhesive failure. SBS in Group $\mathcal{A}$ was significantly lower than either groups showing an adhesive failure at the zirconia- adhesive interface.

CONCLUSIONS: Both Assure Plus + Silane and the classical ceramic bonding protocol achieved clinically acceptable SBS of ceramic brackets bonded to glazed zirconia. However, Assure Plus + Silane achieved better debonding characteristics.
Keywords: Shear bond strength, ceramic brackets, zirconia, glazed, Assure Plus, MDPP

\section{Introduction}

The introduction of acid etching by Buonocore(1) made it possible to directly bond orthodontic attachments to enamel(2). Direct bonding of brackets is considered the state of art in modern orthodontic practice. As more adults started to seek orthodontic treatment(3), novel techniques are continuously introduced to bond brackets to the different restorative materials frequently encountered in the adult dentitions(4). In addition, many adults may opt to choose ceramic brackets because of higher esthetic concern compared to adolescents(5).

Zirconia was introduced initially as a material for posterior restorations owing to its excellent mechanical properties(6,7)such as increased hardness, strength, fracture toughness, and wear resistance $(8,9)$. However, its greater opacity precluded its use in anterior restoration.Recently, highly translucent zirconia meets the esthetic requirements of anterior restorations $(10,11)$. Unfortunately, this adds to the practical challenge of distinguishing between zirconia from other glass-based ceramics without damaging the ceramic surface resulting in laborious polishing steps following debonding. One way to address this conundrum is to devise protocol amenable to all ceramic surfaces. Bonding to non-glazed zirconia poses a few challenges in restorative dentistry. The

${ }^{1}$ Resident, Deparment of Orthodontics, Faculty of Dentistry, Alexandria University, Egypt.

${ }^{2}$ Professor, Department of Dental Biomaterials, Faculty of Dentistry, Alexandria University, Egypt.

${ }^{3}$ Lecturer, Department of Orthodontics, Faculty of Dentistry, Alexandria University, Egypt.

${ }^{4}$ Assistant Professor, Department of Orthodontics, Faculty of Dentistry, Alexandria University, Egypt. 
classical bonding protocol to glass ceramics involve the use of hydrofluoric acid (HF) to dissolve the glass phase followed by silane as a coupling agent to methacrylate terminal groups of composites and resin cements(12).Being a non-silica-based ceramic, HF cannot sufficiently roughen the surface of non-glazed zirconia for micromechanical retention(13). In addition, the lack of a glass substrate precludes the use of silane as a coupling agent(14). However, facial and lingual surfaces of zirconia restoration, where orthodontic brackets are bonded, are conventionally glazed(15). Owing to its silica-based composition, the glaze can provide a substrate amenable to classical ceramic bonding protocols using $\mathrm{HF}$ and silane. However, it is questionable whether the glaze can secure sufficient bond strength for orthodontic purposes. Moreover, the glaze layer may be totally or partially removed during the mechanical preparation of the surface exposing the underlying silica-free zirconia that is difficult to bond to. Phosphate-monomerbased primers were marketed as all surface bonding agent to bond directly to non-silica based ceramics such as zirconia and indirectly to silica-based glass ceramics via silane on one side, and to methacrylate terminal groups of composites and resin cements on the other side $(16,17)$. Assure Plus (Reliance Orthodontics Products, IL, USA), is a phosphate monomer based on MethacryloyloxydecylDihydrogenPhosphate (MDP). Reliance proposed a universal technique for bonding to all ceramic surfaces based on the mechanical roughing of the surface using air abrasion with aluminum oxide $\mathrm{Al}_{2} \mathrm{O}_{3}$ followed by chemical conditioning using both silane and Assure Plus(18). To our knowledge, no previous study evaluated this proposed protocol.
There is a paucity of studies evaluating the SBS of ceramic brackets to glazed zirconia(19,20). To our knowledge, Assure Plus was not studied using ceramic brackets. Previous studies using Assure Plus tested either SBS using metal brackets on non-glazed zirconia(21) or tensile bond strength (TBS) using metal attachment hooks on glazed zirconia(22). Being a primer specifically marketed for orthodontic bonding warranted the evaluation of its performance.

Hence, we conducted this study to answer the following questions:

1. Does the use of an MDP alone provide an adequate bond of ceramic brackets to glazed zirconia?

2. Does the use of the universal technique provide acceptable SBS of ceramic brackets to zirconia or the addition of silane will interfere with the MDP primer?

3. Will the classical porcelain bonding protocol achieve an acceptable bond strength to glazed zirconia?

\section{Materials and Methods}

\section{Specimens}

Forty five rectangular shaped Y-TZP monolithic zirconia discs (Kuraray Noritake, Dental Inc., Japan)were sectioned and sintered at $1530^{\circ} \mathrm{C}$ for $8 \mathrm{~h}$ in a sintering furnace (MIHM-VOGT GmbH \& Co, Germany), according to manufacturer's instructions, measuring $5 \mathrm{~mm}$ × $7 \mathrm{~mm} \times 1.5 \mathrm{~mm}$ post sintering. Two layers of glaze (VITA AKZENT Plus, Vita Zahnfabrik, Bad Säckingen, Germany) were applied on the sintered discs, eachlayer fired at $820^{\circ} \mathrm{C}$ for 10 min in a ceramic furnace. All samples were subsequently embedded in acrylic cylinders with self-cure acrylic resin. The specimens 
were randomly assigned to 3 groups $(n=15)$ according to the bonding protocol.

\section{Procedures}

All specimens were pumiced using a lowspeed contra-angle handpiece with a rubber cup and oil-free pumice, rinsed and driedwith warm air from a hairdryer. All drying steps were done using warm air from a hairdryer to avoid possible oil or moisture contamination with the air-water syringe.

All specimens underwent air abrasion with $50 \mu \mathrm{m} \mathrm{Al}{ }_{2} \mathrm{O}_{3}$ using the MicroEtcher IIA Intraoral Sandblaster (Danville Materials, CA, USA) for $5 \mathrm{~s}$ at $5 \mathrm{~mm}$ perpendicular to the bonding surface at a pressure of $40 \mathrm{psi}$.

In group $\mathrm{A}$, one layer of Assure Plus (Reliance Orthodontics Products, IL, USA) was applied and photo polymerized for $15 \mathrm{~s}$ using a light emitting diode (LED) curing unit (FlashMax P3 light curing unit, Cms Dental, Denmark) at $5000-6000 \mathrm{~mW} / \mathrm{cm}^{2}$. In group $\mathrm{B}$, one coat of silane (Reliance Orthodontics Products, IL, USA) was applied with a bristle brush, allowed to remain on the surface for 3 min then air dried for $30 \mathrm{~s}$, followed by the application of one layer of Assure Plus in the previously described manner. Specimens in Group C were etched with 4\% HF acid (Reliance Orthodontics Products, IL, USA) for $4 \mathrm{~min}$, rinsed for $15 \mathrm{~s}$, and air dried, followed by the application of silane, as previously described, and one layer of Transbond XT primer (3M Unitek, Monrovia, CA, USA) was applied and light cured for $15 \mathrm{~s}$.

Monocrystalline ceramic brackets (Perfect Clear II Sapphire, Hubit Products Co. Ltd., Dongan-gu, Republic of Korea) were subsequently bonded using Transbond XT paste (3M Unitek, Monrovia, CA, USA) in all groups. The brackets were light cured for $15 \mathrm{~s}$ on the mesial and $15 \mathrm{~s}$ on the distal sides of the bracket. Groups A and B (containing Assure Plus) were cured double the curing time.

After the bonding procedures, all specimens were stored at $37^{\circ} \mathrm{C}$ in distilled water for $24 \mathrm{~h}$. The specimens were then subjected to 500 cycles of $5^{\circ} \mathrm{C}-55^{\circ} \mathrm{C}$ thermocycling with a dwell time of $30 \mathrm{~s}$, to simulate intraoral environment, following the ISO standard protocol 11405(23).

\section{Assessment}

SBS was tested using a Universal testing machine (Model 3345, Instron, Norwood, MA, USA). A chisel cross-head was applied at a speed of $1.00 \mathrm{~mm} / \mathrm{min}$ and cell load of 500 N(Fig.1). SBS was calculated using a computer software BluehillInstron dividing the load at fracture $(\mathrm{N})$ to the surface area of the bracket base $\left(\mathrm{mm}^{2}\right)$. The dimensions of the bracket $(3.2$ x $3.8 \mathrm{~mm}$ ) were provided by the manufacturer. 

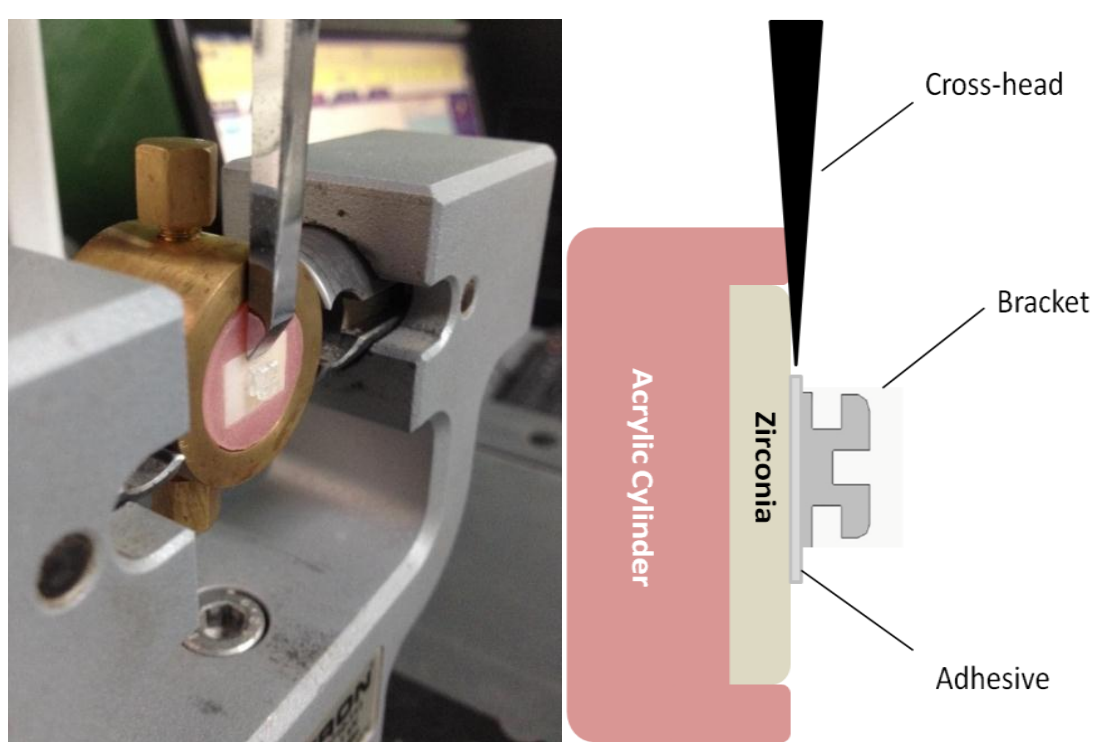

Fig. 1: Left:Shear bond strength testing using the Universal testing machine; Right:Diagrammatic illustration of the testing set-up.

The debonded specimens and the base of the brackets were examined under a Stereomicroscope at $18 \mathrm{x}$ magnification(Olympus SZ1145TR, Japan) and photographed using a digital camera (ToupCam, XCAM1080PHB, Japan). Mode of failure was assessed as follows(24):

A: Adhesive Failure between zirconia and adhesive

B: Complex adhesive and cohesive failure

$\mathrm{C}$ : Adhesive failure between adhesive and bracket base

Adhesive Remnant Index was scored as follows(25):

0 : No adhesive remaining on the specimen in the bonded area

1: Less than half the bonded area covered by the adhesive

2: More than half the bonded area covered by the adhesive

3: All adhesive remaining on the entire bonded area
To study the effect of air abrasion on the glaze layer, 3 additional specimens were subjected to air abrasion and analyzed using a scanning electron microscopeoperating between 15 and $20 \mathrm{KeV}$ (Jeol JSM- 5300).

Sample size, Method error \& Statistical Analysis

G Power computer softwarewas used to calculate the sample size. ${ }^{(26)}$ Using an independent sample t-test, at $\alpha=0.05$ and $95 \%$ power, a mean difference of $3 \mathrm{MPa}^{(27,28)}$ and standard deviation of $2.5 \mathrm{MPa}{ }^{(27,28)}$

Calibration of the Instron 3345 Universal Materials Testing Machine ID: 3345L6223, was carried out by the Instron North Africa services calibration center on the 10.01.2019. Intra- and inter-examiner reliability were tested for the failure mode and ARI. Nine specimens were randomly selected and scored by an independent examiner and rescored by the principal investigator 2 weeks following the initial scoring. The agreement between the qualitative Kappa test showed excellent agreement. 
Data was analyzed using IBM SPSS statistical software version 25 (SPSS Inc., Illinois, Chicago, USA). Normality was checked using descriptive statistics, plots (Histograms \& Box plots) and Shapiro Wilk test. SBS were compared using one-way analysis of variance (ANOVA). Post-hoc multiple comparisons were done using Games Howell. Chi-square tests were used to compare ARI and failure modes. A survival analysis was conducted by plotting cumulative probability of bond failure against the applied shear stress for each group(29). Significance level for all statistical tests was set at $P \leq 0.05$.

Table 1.Comparison of the shear bond strength (SBS) among the groups

\section{Results}

Mean, standard deviation, minimum and maximum SBS values are shown in Table 1. Group C showed the highest SBS followed by Group B. Group A showed the lowest SBS with one specimen debonded after thermocycling. One-way ANOVA showed a statistically significant difference between the 3 groups $(P \leq 0.0001)$. Group A had significantly lower SBS than group B ( $P$ $<0.0001)$ and $\mathrm{C}(P<0.0001)$. No statistically significant difference was found between Group B and C (Table 1). The survival curve indicated that $19.9 \%$ of brackets in Group B failed at $6 \mathrm{MPa}$, the minimally acceptable $\mathrm{SBS}^{(30)}$, compared to $13.3 \%$ in group C, whereas group A did not reach the threshold for clinically acceptable bond strength (Fig. 2)

\begin{tabular}{lcccccc}
\hline \multicolumn{1}{c}{ SBS } & $\begin{array}{c}\text { Group A } \\
(n=14)\end{array}$ & $\begin{array}{c}\text { Group B } \\
(n=15)\end{array}$ & $\begin{array}{c}\text { Group C } \\
(n=15)\end{array}$ & $\begin{array}{c}\text { Group B }- \\
\text { Group A }\end{array}$ & $\begin{array}{c}\text { Group C- } \\
\text { Group A }\end{array}$ & $\begin{array}{c}\text { Group C- } \\
\text { Group B }\end{array}$ \\
\hline Mean $(S D)$ & $2.50(0.75)$ & $7.81(2.81)$ & $8.15(2.41)$ & $5.31(2.90)$ & $5.66(2.52)$ & $0.34(3.70)$ \\
Min-Max & $1.36-3.69$ & $2.43-13.18$ & $5.47-13.41$ & & & \\
$95 \%$ C.I. & & & & $(3.37,7.25)$ & $(3.98,7.33)$ & $(-2.02,2.71)$ \\
$P$ value & & & & $<0.0001^{*}$ & $<0.0001^{*}$ & 0.93 \\
\hline
\end{tabular}

* Statistically significant at $P$ value $\leq 0.05$.

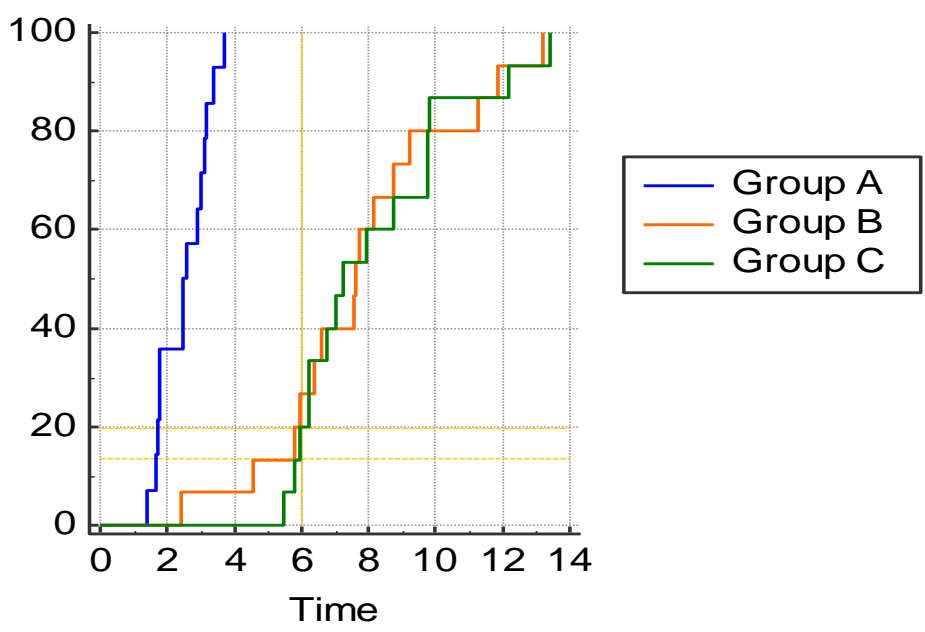

Fig. 2:Cumulative probability of failure across the groups 
Both failure mode and ARI scores were significant different between the groups $\left(\mathrm{X}^{2}=\right.$ 51.32, 61.96; $P<0.0001,<0.0001$; respectively). Most of the specimens in Group $\mathrm{C}$ showed an adhesive failure between the bracket base and the adhesive, whereas Group B presented mainly a mixed cohesive adhesive failure. All specimens in Group A showed an adhesive failure at the zirconia- adhesive interface. None of the specimens showed zirconia or bracket fracture.

The scanning electron micrographs showed that air abrasion produced superficial irregularities and surface roughness of the glaze without exposing the underlying zirconia (Fig. 4).
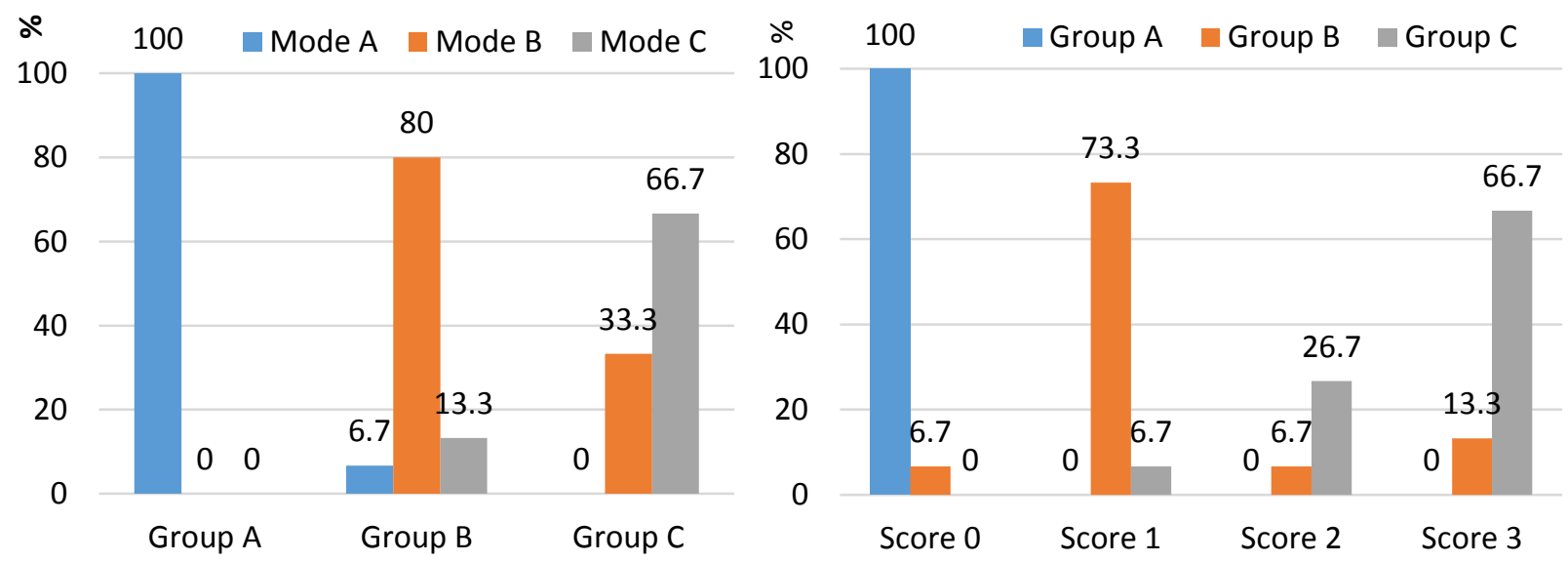

Fig. 3: Left: Failure mode; Right: Adhesive Remnant Index (ARI) across the study groups.

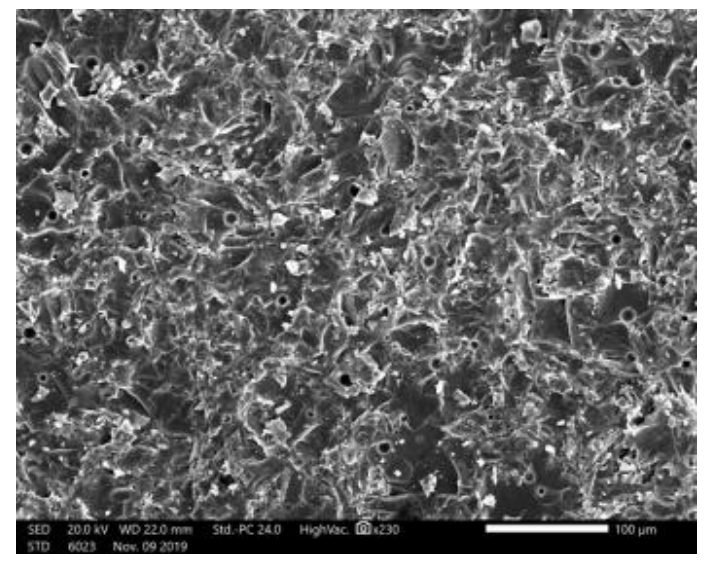

Fig. 4: Representative SEM image of glazed zirconia discs after sandblasting with $\mathrm{Al}_{2} \mathrm{O}_{3}$, showing superficial irregularities and surface roughness of the glaze, the underlying zirconia was not exposed (Magnification x 230).

\section{Discussion}

The clinically acceptable SBS for orthodontic purposes was suggested to be within the range of $5.8-7.8 \mathrm{MPa}{ }^{(30,31)}$
Accordingly, groups $\mathrm{B}$ and $\mathrm{C}$ are clinically useable, whereas group A is of no clinical use. However, owing to the more favorable failure mode and clinically acceptable SBS, group B appears to perform better. 
Group A showed the lowest SBS that was significantly lower compared to groups B (Air abrasion + silane) and $\mathrm{C}$ (Air abrasion + $\mathrm{HF}+$ silane + Transbond XT primer). The bonding protocol in Group A (Air abrasion + Assure Plus) was tested by Mehta et al. ${ }^{(22)}$ Assure Plus on sandblasted glazed zirconia yeilded a TBS of $5.32 \pm 0.52 \mathrm{MPa}$, which was the highest bond strength among the protocols tested. However, the TBS of metal brackets to nonthermocycled zirconia specimens may explain the difference in bond strength. It can be argued that SBS may yield lower results attributed to the stress concentration as a result of the technique. Computer simulations using finite element analysis reported higher stress concentration at the load application area when a knife-edge chisel was applied, using a wire loop on the other hand showed that load was distribiuted over the entire contact area between wire loop and specimen. ${ }^{(12)}$ Despite the existing controversy, thermocycling is generally found to reduce bond strength values $^{(32)}$. Several studies used the same bonding protocol in Group A albeit with phosphate monomer primers other than Assure Plus on glazed zirconia. Lee J. H. et al. ${ }^{(24)}$ tested Zirconia Liner Premium using metal brackets with a combined surface treatment of HF etching and air abrasion. It was found that phostphate monomer primer resulted in a statistically significant lower SBS $(3.85 \pm 1.33$ $\mathrm{MPa})$ compared to the addition of silane $(14.51 \pm 3.11 \mathrm{MPa})$, which support the findings of this study. Kwak et al. ${ }^{(28)}$ tested Z-PRIME Plus on glazed zirconia. Air abrasion resulted in significantly lower SBS $(4.60 \pm 1.08 \mathrm{MPa})$ compared to diamond bur roughening $(\mathrm{SBS}=$ $15.48 \pm 3.15 \mathrm{MPa}$ ) which may be attributed to the complete removal of the glaze layer exposing the underlying zirconia that is more amenable to bonding to phosphate monomer primers.
All the specimens in group A showed an adhesive failure between zirconia and the adhesive, reflecting to the low SBS values. It can be assumed that Assure Plus alone is not enough to bond to glazed zirconia, since conservative surface treatments such as air abrasion do not guarantee the complete removal of the glaze and the exposure of underlying zirconia. Similar results were reported by both Lee J. H. et al. ${ }^{(24)}$ and Kwak et al. ${ }^{(28)}$. Conversely, Mehta et al. ${ }^{(22)}$ found a predominantly adhesive bond failure between the bracket and adhesive. Since all the tested groups showed either mainly adhesive bond failure between the bracket and adhesive or mixed cohesive-adhesive failure it was suggested that the traction hook was not sufficiently retentive.

Group B (Air abrasion + silane + Assure Plus), showed the second highest SBS (7.80 \pm $2.80 \mathrm{MPa})$. Although the universal technique using Assure Plus and silane was not previously tested with ceramic brackets and glazed zirconia, several studies used a combination of silane and phosphate ester monomer, either individually or in the form of products containing both chemicals, however metal brackets were tested on glazed zirconia. Lee J. H. et al. ${ }^{(24)}$ primed the specimens with silane and Zirconia Liner Premium resulting in a SBS of $14.51 \pm 3.11 \mathrm{MPa}$. The higher SBS can be explained by the treatment of zirconia by both air abrasion followed by HF. In addition, Zirconia Liner Premium contains 4Methoxyphenol in addition to phosphate ester monomer, both of which chemically bond to zirconia $^{(33)}$. Bavbek et al. ${ }^{(34)}$ tested Monobond Plus, an all ceramic primer containing both silane and phosphate monomer. The results presented a micro-SBS of $30.0 \pm 3.8 \mathrm{MPa}$. This may be attributed to the lack of thermocycling and the different type of test used. Microshear 
bond strength testing does not reflect the variance of bond strength throughout the bonding area. Amer and Rayyan ${ }^{(35)}$ used Clearfil Ceramic Primer, a one-bottle MDP and silane primer. The higher reported SBS (20.8 \pm $4.8 \mathrm{MPa}$ ) may be attributed to the use of Panavia resin cement which contains MDP. Generally, resin cements result in higher bond strength compared to composite resins. ${ }^{(36)}$ Ihsan et al. ${ }^{(37)}$ reported SBS of $16.29 \pm 2.20$ MPa with Single Bond Universal, composed of both silane and MDP. However, the specimens were not thermocycled.

In group $B$, the failure mode was predominantly a mixed cohesive-adhesive failure. Similarly, Lee J.H. et al. ${ }^{(24)}$ reported a similar failure mode in the specimens treated with a comparable bonding protocol. On the other hand, Bavbek et al. ${ }^{(34)}$ and Amer and Rayyan $^{(35)}$ found the majority of specimens to fail at the zirconia-adhesive interface, despite the higher reported $\mu$ SBS and SBS values. Conversely, Ihsan et al. ${ }^{(37)}$ reported an adhesive failure at the base in most specimens. The difference in the composition between Monobond Plus, ${ }^{(34)}$ Clearfil Ceramic Primer ${ }^{(35)}$ and Single Bond Universal ${ }^{(37)}$ may explain the difference. Direct comparison between different products may prove difficult since each has a proprietary composition aimed at optimizing its performance.

Group C (Air abrasion + HF + silane + Transbond XT primer) which was meant to test the bonding to glaze showed the highest SBS $(8.15 \pm 2.40 \mathrm{MPa})$. However, no statistically significant difference between group $\mathrm{C}$ and $\mathrm{B}$ was found. Similar results were reported by Mehmeti et al. ${ }^{(20)}$ for ceramic brackets bonded to glazed zirconia using $\mathrm{HF}$ and silane $(8.99 \pm$ $5.36 \mathrm{MPa})$. On the other hand, Lee J.H. et al. ${ }^{(24)}$ found the higher SBS $(16.29 \pm 4.88 \mathrm{MPa})$ using this bonding protocol with metal brackets. Conversely, Yassaei et al. ${ }^{(38)}$ reported lower SBS of $5.84 \pm 0.78 \mathrm{MPa}$. Using diamond bur roughening, the glaze may have been removed resulting in insufficient silica to chemically bond to silane. The failure mode in Group $\mathrm{C}$ was predominantly an adhesive failure at the bracket base where most of the adhesive remained attached to zirconia, suggesting a stronger bond to glazed zirconia than to the ceramic bracket base. Similar failure modes using the same protocols were reported. ${ }^{(22,24)}$ However, Mehmeti et al. ${ }^{(20)}$ found the majority of ceramic brackets to present an adhesive failure at the zirconia-resin interface which may be attributed to the different ceramic brackets tested.

Collectively, studies comparing silane to phosphate monomer primers on glazed zirconia showed controversial results. Lee J. H. et al. ${ }^{(24)}$ found higher SBS of silane compared to Zirconia Liner Premium. Conversely, Mehta et al. ${ }^{(22)}$ reported the highest TBS with Assure Plus, followed by silane followed by ZPRIME, a phosphate monomer. This may be explained by the disparate surface treatments used in the different studies including air abrasion protocols, the use of HF or the lack there of; both of which would affect the amount of glaze removed, which is difficult to standardize in the first place. On the other hand, studies on non-glazed zirconia showed consistently the superiority of phosphate monomer primers. ${ }^{(27,39-42)}$

Most clinicians would prefer a failure rate of less than $5 \% .{ }^{(43)}$ The survival analysis demonstrates the distribution of SBS that might get reduced by reporting the mean. ${ }^{(29)}$ In this study, the failure rates of the clinically useable groups were well above $10 \%$. Hence, despite the acceptable mean SBS of groups B and C, the higher failure percentages may leave more to be desired in terms of bond strength. 
Based on the results of this study, it is to be assumed that Assure Plus alone is not sufficient to achieve a clinically acceptable bond of orthodontic brackets to glazed zirconia. Since the thickness of the glaze layer may vary greatly between laboratories, one might question the efficacy of the different surface treatments in totally exposing the underlying zirconia. One can advise the use of a porcelain conditioner (silane) in combination with a primer containing phosphate ester monomer, such as Assure Plus to achieve optimum bonding to zirconia.

An in vitro study cannot perfectly replicate all the oral environment. Some of the limitations of in vitro studies include the short time interval between the bonding and the debonding procedures. Despite the use of thermocycling, the potential influence of the oral environment on the bonding material cannot be replicated. Factors such as degradation by saliva, $\mathrm{pH}$ and microbial contamination are disregarded. However, it offers the ability to test bond strength in the laboratory under standardized condition.

\section{Conclusions}

Within the limitations of this study, it can be concluded that:

1. The "Zirconia specific" protocol (SB + Assure Plus) did not achieve proper bond strength of ceramic brackets to glazed zirconia.

2. The "All ceramic" protocol (SB + Silane + Assure Plus) and the "Traditional" bonding protocol for porcelain $(\mathrm{SB}+\mathrm{HF}+$ Silane + Transbond XT primer) achieved clinically acceptable SBS of ceramic brackets bonded to glazed zirconia.

3. The "All ceramic" protocol showed superior debonding characteristics with mixed cohesive and adhesive bond failure compared to the "Traditional" bonding protocol which showed adhesive failure at the adhesivebrackets interface.

\section{References:}

1. Buonocore MG. A simple method of increasing the adhesion of acrylic filling materials to enamel surfaces. J Dent Res. 1955;34:849-53.

2. Newman GV. Epoxy adhesives for orthodontic attachments: progress report. Am J OrthodDentofacialOrthop. 1965;51:901-12.

3. Buttke TM, Proffit WR. Referring adult patients for orthodontic treatment. J Am Dent Assoc. 1999;130:73-9.

4. Trakyalı G, Malkondu Ö, Kazazoğlu E, Arun T. Effects of different silanes and acid concentrations on bond strength of brackets to porcelain surfaces. Eur J Orthod. 2009;31:4026.

5. Oliveira SC, Furquim RD, Ramos AL. Impact of brackets on smile esthetics: laypersons and orthodontists perception. Dental Press J Orthod. 2012;5:64-70.

6. Cavalcanti AN, Foxton RM, Watson TF, Oliveira MT, Giannini M, Marchi GM. Y-TZP ceramics: key concepts for clinical application. Oper Dent. 2009;34:344-51.

7. Nakonieczny D, Walke W, Majewska J, Paszenda Z. Characterization of magnesiadoped yttria-stabilized zirconia powders for dental technology applications. ActaBioengBiomech. 2014;16:99-106.

8. Kosmač T, Oblak Č, Jevnikar P, Funduk N, Marion L. Strength and reliability of surface treated Y-TZP dental ceramics. J Biomed Mater Res. 2000;53:304-13. 
9. El-Korashy DI, El-Refai DA. Mechanical properties and bonding potential of partially stabilized zirconia treated with different chemomechanical treatments. J Adhes Dent. 2014;16:365-76.

10. Raigrodski AJ, Chiche GJ, Potiket N, Hochstedler JL, Mohamed SE, Billiot S, Mercante DE. The efficacy of posterior threeunit zirconium-oxide-based ceramic fixed partial dental prostheses: A prospective clinical pilot study. J Prosthet Dent. 2006;96:237-44.

11. Örtorp A, Kihl ML, Carlsson GE. A 3-year retrospective and clinical follow-up study of zirconia single crowns performed in a private practice. J Dent. 2009;37:731-6.

12. Sakaguchi R, Ferracane J, Powers J. Materials for Adhesion and Luting. In Sakaguchi R, Ferracane J, Powers J (Editors) Craig's Restorative Dental Materials. Chapter 13 , page 281 .

13. Thompson JY, Stoner BR, Piascik JR, Smith R. Adhesion/cementation to zirconia and other non-silicate ceramics: where are we now?. Dent Mater. 2011;27:71-82.

14. Matinlinna JP, Lassila LV, Özcan M, YliUrpo A, Vallittu PK. An introduction to silanes and their clinical applications in dentistry.Int $\mathbf{J}$ Prosthod. 2004;17:155-164.

15. Zhang Y, Kim JW. Graded structures for damage resistant and aesthetic all-ceramic restorations. Dent Mater. 2009;25:781-90.

16. Yoshida K, Tsuo Y, Atsuta M. Bonding of dual-cured resin cement to zirconia ceramic using phosphate acid ester monomer and zirconate coupler. J Biomed Mater Res. 2006;77:28-33

17. Kern M, Barloi A, Yang B. Surface conditioning influences zirconia ceramic bonding. J Dent Res. 2009;88:817-22.
18. Reliance Orthodontic Products, Inc. Assure Plus [Instructions]. Itasca, IL: Reliance Orthodontic Products, Inc; 2017.

19. Mehmeti B, Azizi B, Kelmendi J, IljaziShahiqi D, Alar Ž, Anić-Milošević S. Shear bond strength of orthodontic brackets bonded to zirconium crowns. Acta Stomatol Croat. 2017;51(2):99-105.

20. Mehmeti B, Kelmendi J, Iiljazi-Shahiqi D, Azizi B, Jakovljevic S, Haliti F, AnićMilošević S. Comparison of Shear Bond Strength Orthodontic Brackets Bonded to Zirconia and Lithium Disilicate Crowns. ActaStomatol Croat. 2019;53:17-27.

21. Reichheld T, Monfette G, Perry RD, Finkelman M, Gheewalla E, Kugel G. Clinical Significance of Bis-GMA and HEMA Orthodontic Resins Bonding to Enamel and Ceramic Materials. Compend Contin Educ Dent. 2016;37:e5-8.

22. Mehta AS, Evans CA, Viana G, BedranRusso A, Galang-Boquiren MT. Bonding of metal orthodontic attachments to sandblasted porcelain and zirconia surfaces. Biomed Res Int. 2016;1-6.

23. International Standardization Organization. Guidance on testing of adhesion to tooth structure. International Organization for Standardization. Geneva (Switzerland). 2015;TR 11405: 1-12.

24. Lee JH, Lee M, Kim KN, Hwang CJ. Resin bonding of metal brackets to glazed zirconia with a porcelain primer. Korean J Orthod. 2015;45:299-307.

25. Maijer R, Smith DC. Variables influencing the bond strength of metal orthodontic bracket bases. Am J Orthod. 1981;79:20-34. 
26. Faul F, Erdfelder E, Lang AG, Buchner A. $G^{*}$ Power 3: A flexible statistical power analysis program for the social, behavioral, and biomedical sciences. Behav Res methods. 2007;39(2):175-91.

27. Lee JY, Kim JS, Hwang CJ. Comparison of shear bond strength of orthodontic brackets using various zirconia primers.Korean $\mathrm{J}$ Orthod. 2015;45:164-70.

28. Kwak JY, Jung HK, Choi IK, Kwon TY. Orthodontic bracket bonding to glazed fullcontour zirconia. Restor Dent Endod. 2016;41:106-13.

29. Karan S, Büyükyılmaz T, Toroğlu MS. Orthodontic bonding to several ceramic surfaces: are there acceptable alternatives to conventional methods? Am J OrthodDentofacialOrthop. 2007;132:144-7.

30. Reynolds IR. A review of direct orthodontic bonding.Br J Orthod. 1975;2:1718.

31. Whitlock III BO, Eick JD, Ackerman Jr RJ, Glaros AG, Chappell RP. Shear strength of ceramic brackets bonded to porcelain. Am J OrthodDentofacialOrthop. 1994;106:358-64.

32. Amaral FL, Colucci V, PALMA-DIBB RG, Corona SA. Assessment of in vitro methods used to promote adhesive interface degradation: a critical review. J EsthetRestor Dent. 2007;19:340-53.

33. Kumbuloglu O, Lassila LV, User A, Vallittu PK. Bonding of resin composite luting cements to zirconium oxide by two air-particle abrasion methods. Oper Dent. 2006;31:248-55.

34. Bavbek NC, Roulet JF, Ozcan M. Evaluation of microshear bond strength of orthodontic resin cement to monolithic zirconium oxide as a function of surface conditioning method. J Adhes Dent. 2014; 16:473-80.
35. Amer JY, Rayyan MM. Effect of different surface treatments and bonding modalities on the shear bond strength between metallic orthodontic brackets and glazed monolithic zirconia crowns. J Orthod Sci. 2018;7:23-30.

36. Ireland AJ, Sherriff M. Use of an adhesive resin for bonding orthodontic brackets. Eur J Orthod. 1994;16:27-34.

37. Ihsan SS, Mohammed SA. Comparison of Shear Bond Strength of Orthodontic Buccal Tube Bonded to Zirconia Crown after Using Two Different (10-MDP)-Containing Adhesive Systems. Health Sci. 2019;8:69-78.

38. Yassaei S, Aghili HA, Davari A, Mostafavi SM. Effect of four methods of surface treatment on shear bond strength of orthodontic brackets to zirconium. J Dent (Tehran, Iran). 2015;12:281-9.

39. Kim NH, Kim YJ, Lee DY. Bond Strengths of Orthodontic Metal Brackets to Tribochemically Silica-coated Zirconia Surfaces Using Different 10Methacryloyloxydecyl Dihydrogen Phosphatecontaining Primers. J Adhes Dent. 2017;19:2129.

40. Byeon S, Lee M, Bae T. Shear bond strength of $\mathrm{Al}_{2} \mathrm{O}_{3}$ sandblasted Y-TZP ceramic to the orthodontic metal bracket. Materials. 2017;10:148-162.

41. Dong JC, Wen LM, Li R, Li JY. The influence of different treating agents on the shear bond strength between zirconia and orthodontic brackets. Shanghai J Stomatol. 2016;25:177-80.

42. Kim J, Park C, Lee JS, Ahn J, Lee Y. The effect of various types of mechanical and chemical preconditioning on the shear bond strength of orthodontic brackets on zirconia restorations.Scanning. 2017;1-10. 
43. Miles PG, Pandis N, Eliades T. Bonding and adhesives in orthodontics. In Miles, P. G., Rinchuse, D. J., \& Rinchuse, D. J. (Editors). E
Evidence-based clinical orthodontics. Chapter $3: 47-9$. 